\title{
DETERMINATION OF MEFENAMIC ACID IN A TOPICAL EMULGEL BY A VALIDATED HPLC METHOD
}

\section{APICHART ATIPAIRIN ${ }^{1,2 *}$, SOMCHAI SAWATDEE ${ }^{1,2}$}

\author{
${ }^{1}$ Drug and Cosmetics Excellence Center, ${ }^{2}$ School of Pharmacy, Walailak University, Thaiburi, Thasala, Nakhon Si Thammarat, 80160, \\ Thailand \\ Email: apichart.at@wu.ac.th
}

Received: 15 Aug 2019, Revised and Accepted: 23 Sep 2019

\section{ABSTRACT}

Objective: The present study is aimed to develop and validate a simple, precise and accurate high-performance liquid chromatography (HPLC) method, according to ASEAN guideline for the validation of the analytical procedure, for the determination of mefenamic acid in a topical emulgel preparation.

Methods: An emulgel of $1 \%$ mefenamic acid was prepared using carbopol 940 as a gelling agent and cremophor EL as an emulsifying agent. It was diluted with ethanol to make a sample concentration of $200 \mu \mathrm{g} / \mathrm{ml}$. The method used a C18 column $(5 \mu \mathrm{m} ; 250 \times 4.6 \mathrm{~mm})$ with the mobile phase, consisting of acetonitrile, acetic acid, and water in a ratio of 75:1:24. The column was maintained at $25^{\circ} \mathrm{C}$. The flow rate was $1 \mathrm{ml} / \mathrm{min}$ and the injection volume was $10 \mu \mathrm{l}$. The peak response was monitored by UV at $282 \mathrm{~nm}$. It was validated for specificity, range, linearity, precision, accuracy, limit of detection (LOD) and limit of quantification (LOQ). In addition, forced degradation (hydrolysis, oxidation and dry heat) was performed to determine the capability of the proposed method to analyze the chemical stability of the drug samples during storage.

Results: The method was specific to the drug while other excipients did not interfere with the quantitation of mefenamic acid. It was linear in the concentration range of 1.29 to $806 \mu \mathrm{g} / \mathrm{ml}$. LOD and LOQ were 4.88 and $14.78 \mu \mathrm{g} / \mathrm{ml}$, respectively. Accuracy of the method was demonstrated by recovery experiments on the synthetic mixture method and the mean percent recovery was $101.10 \pm 1.56$. Repeatability and intermediate precision were rugged with \%RSD values of 1.30 and 1.07, respectively. The method could separate mefenamic acid from other degradation products of forced degradation.

Conclusion: The HPLC method presented herein is simple, accurate, sensitive and reproducible for the determination of mefenamic acid in an emulgel. It is served as a stability-indicating method and can be used for the analysis of the drug during product development and stability studies.

Keywords: ASEAN guideline, Emulgel, HPLC, Mefenamic acid, Stability-indicating method

(c) 2019 The Authors. Published by Innovare Academic Sciences Pvt Ltd. This is an open-access article under the CC BY license (http://creativecommons.org/licenses/by/4.0/) DOI: http://dx.doi.org/10.22159/ijap.2019v11i6.35348

\section{INTRODUCTION}

Mefenamic acid or 2-(2,3-dimethyl phenyl) aminobenzoic acid (fig 1 ) is a nonsteroidal anti-inflammatory drug (NSAID). It is often used for the treatment of mild to moderate pain, including headache, fever, dysmenorrhea, osteoarthritis, rheumatoid arthritis and inflammation [1]. The drug is classified as a biopharmaceutical classification system (BCS) class II that has low water solubility but high permeability [2]. It is conventionally available in the form of a tablet, capsule, and suspension for oral administration. The absolute bioavailability of the drug is about $90-100 \%$ by which the dissolution is the critical process in drug absorption [3]<smiles>Cc1cccc(Nc2ccccc2C(=O)O)c1C</smiles>

Fig. 1: Chemical structure of mefenamic acid

Topical preparation is another potential formulation that is used for the localized effect at the site of its application. Emulgel is a promising topical preparation for the delivery of hydrophobic drugs such as mefenamic acid, diclofenac, ketoprofen and ketoconazole [46]. It is an emulsion that is gelled by gelling agents. This preparation has many advantages; for example delivery of poorly soluble drugs at a specific site, avoidance of gastrointestinal incompatibility and more patient compliance. Several attributes of emulgel are characterized to ensure the quality and consistency of drug products. UV spectrophotometry and high-performance liquid chromatography (HPLC) are often used to analyze the content of mefenamic acid in raw material, tablet dosage form and human plasma [7-9]. Binhashim and Hammami developed an HPLC method to determine mefenamic acid in human plasma [10]. They used diclofenac as an internal standard and the drugs were separated on a C18 column with a mobile phase of $0.025 \mathrm{M}$ phosphate buffer $\mathrm{pH}$ 6.0 and acetonitrile (65:35). This method was accurate and suitable for use in stability study because no interference was co-eluted with mefenamic acid and the limit of quantification (LOQ) of the drug was acceptable $(0.05 \mu \mathrm{g} / \mathrm{ml})$. Kumar et al. simultaneously determined mefenamic acid, dicyclomine $\mathrm{HCl}$ and pamabrom in a tablet. They used a C18 column as a stationary phase and a mixture of $20 \mathrm{~mm}$ potassium dihydrogen orthophosphate $\mathrm{pH} 5.9$ and acetonitrile (30:70) as a mobile phase. The method was followed ICH guideline and the drug was detected at $285 \mathrm{~nm}$, showing the linear range in the concentration of $0.5-15 \mu \mathrm{g} / \mathrm{ml}$. It was an accurate procedure with a mean recovery of $99.73 \pm 0.68 \%$. However, a few studies have developed a UV spectrophotometry to analyze mefenamic acid in emulgel. They dissolved a quantity of gel, containing hydroxypropylmethylcellulose and sodium carboxymethylcellulose as gelling agents, in methanol and the drug content and drug release were determined at $285 \mathrm{~nm}[11,12]$. This method showed linearity over a concentration of $5-30 \mu \mathrm{g} / \mathrm{ml}$ and it was useful for evaluation of the drug in this topical formulation. It has been reported that mefenamic acid is not a stable drug and its degradation products could increase undesirable effects $[13,14]$. However, there is limited information on the stability-indicating HPLC method used to determine the drug content in the emulgel during stability study [15]. This study was aimed to develop and validate an HPLC method to analyze mefenamic acid in an emuslgel, according to ASEAN guideline for the validation of the analytical procedure. Forced 
degradation studies in hydrolysis, oxidation and thermal degradation were also performed to determine the stabilityindicating capability of the method.

\section{MATERIALS AND METHODS}

\section{Chemicals and reagents}

Mefenamic acid was purchased from P. C. drug center Co. Ltd, Thailand and its reference standard were obtained from SigmaAldrich, USA. Cremophor EL was from BASF Corp., USA. Carbopol 940, isopropyl myristate, methylparaben, and propylparaben were purchased from P. C .drug center Co .Ltd, Thailand .Acetonitrile was HPLC grade from RCI Labscan, Thailand.

\section{Preparation of $1 \%$ mefenamic acid emulgel}

Mefenamic acid $(1 \mathrm{~g})$ was dissolved in $2.5 \mathrm{ml}$ of ethanol and the mixture was prepared as the water phase by adding an aliquot of water and $0.5 \%$ paraben concentrate. The oil phase was obtained by mixing $4 \mathrm{ml}$ of cremophor EL and $2 \mathrm{ml}$ of isopropyl myristate. Both phases were incubated at $70{ }^{\circ} \mathrm{C}$ before adding the oil phase into the water phase. The mixture was homogeneously mixed with the gel phase of $0.5 \%$ carbopol 940 and the emulgel product was filled in an aluminum tube.

\section{Preparation of sample solution}

Emulgel sample $(2 \mathrm{~g}$ ) was weighed and transferred into a $50 \mathrm{ml}$ volumetric flask. An aliquot of ethanol $(25 \mathrm{ml})$ was used to dissolve the sample before sonication for $15 \mathrm{~min}$. Ethanol was added to the mark and then a 2-fold dilution with ethanol was performed to make the sample solution $(200 \mu \mathrm{g} / \mathrm{ml})$. It was filtered through a $0.45 \mu \mathrm{m}$ nylon membrane before injection.

\section{Preparation of standard solution}

Mefenamic acid reference standard (100 mg) was accurately weighed and dissolved with ethanol in a $50 \mathrm{ml}$ volumetric flask. The stock solution of the standard was diluted with ethanol to make the working solutions of $20,100,200,400$ and $800 \mu \mathrm{g} / \mathrm{ml}$. They were filtered through a $0.45 \mu \mathrm{m}$ nylon membrane and transferred to $2 \mathrm{ml}$ vials.

\section{Chromatographic condition}

Ultimate 3000 HPLC system (Dionex Corporation, USA) was used to determine the drug content by using Chromeleon 7 software to perform data collection and interpretation. Chromatographic separation was carried out on an Inertsil ${ }^{\circledR}$ ODS-3 C18 column at 25 ${ }^{\circ} \mathrm{C}$ ( $4.6 \times 250 \mathrm{~mm}$, GL Sciences, USA). The mobile phase was the mixture of acetonitrile, acetic acid, and water in a ratio of 75:1:24 and it was pumped at the flow rate of $1.0 \mathrm{ml} / \mathrm{min}$. The injection volume was set at $10 \mu \mathrm{l}$ and the peak response was monitored by UV at $282 \mathrm{~nm}$. The method was validated according to ASEAN guideline for the validation of the analytical procedure (specificity, range, linearity, precision, accuracy, the limit of detection (LOD) and limit of quantification (LOQ) [16].

\section{System suitability test}

The system suitability test was carried out by injections of five replicates of the standard solution $(200 \mu \mathrm{g} / \mathrm{ml})$. General acceptance criteria were in the following; the relative standard deviation (RSD) of the peak response $(\leq 2.0 \%)$, a theoretical plate of the column $(\geq$ $2000)$ and the tailing factor of the peak $(\leq 2.0)$.

\section{Specificity}

Chromatograms of standard solution, sample solution, gel base solution, and standard-spiked sample solution were used to compare the specificity of the method. It must separate the mefenamic acid drug from the other chemicals in the emulgel sample.

\section{Linearity, the limit of detection (LOD) and limit of quantification (LOQ)}

Mefenamic acid reference standard (100 mg) was accurately weighed in triplicate to prepare stock solutions. It was dissolved with ethanol and adjusted the volume to $50 \mathrm{ml}$. The stock solution was diluted with ethanol to make the standard solution at a concentration of $1.28,3.20,8.00,20.0,100,200,400$ and $800 \mu \mathrm{g} / \mathrm{ml}$. Standard calibration curves were constructed by plotting the peak response and the corresponding concentration. Linear regression analysis was used to determine the linearity. LOD and LOQ were calculated by multiplying factors of 3.3 and 10 to a ratio of the standard deviation of the response and the slope of the curve, respectively.

\section{Accuracy}

The accuracy of the proposed method was assessed by making a synthetic mixture. The mefenamic acid standard at three levels $(80 \%$, $100 \%$, and $120 \%$ ) in the emulgel was prepared in the same manner as the sample solution $(160,200$ and $240 \mu \mathrm{g} / \mathrm{ml}$, respectively). It was performed in triplicate and ethanol was used to adjust the volume. These sample solutions were filtered through a $0.45 \mu \mathrm{m}$ membrane filter before analysis. Percent recovery and its standard deviation (SD) were calculated to determine the accuracy [17].

\section{Precision}

Repeatability of the proposed method was determined by injecting six replicates of the sample solutions in the same day. Intermediate precision was assessed by assaying the sample solutions on another day. The precision was presented by the percent relative standard deviation (\%RSD) of the peak response [17].

\section{Forced degradation studies}

\section{Hydrolytic degradation studies}

Mefenamic acid emulgel ( $2 \mathrm{~g}$ ) was dissolved in $30 \mathrm{ml}$ of ethanol. The mixture was transferred into a $50 \mathrm{ml}$ volumetric flask and then sonicated for $15 \mathrm{~min}$. Acid and basic hydrolysis were carried out in triplicate by transferring $5 \mathrm{ml}$ of $1 \mathrm{M} \mathrm{HCl}$ or $1 \mathrm{M} \mathrm{NaOH}$ into the samples. They were refluxed at $80^{\circ} \mathrm{C}$ for $1 \mathrm{~h}$ and subsequently, $5 \mathrm{ml}$ of $1.0 \mathrm{~N} \mathrm{NaOH}$ or $1.0 \mathrm{~N} \mathrm{HCl}$ was added to neutralize the acid and basic samples, respectively. Ethanol was used to adjust the volume of $50 \mathrm{ml}$. The same procedure with distilled water was performed as neutral hydrolysis. The samples were diluted with ethanol to make the sample solutions $(200 \mu \mathrm{g} / \mathrm{ml})$ and filtered through a $0.45 \mu \mathrm{m}$ membrane filter before analysis $[18,19]$.

\section{Thermal degradation studies}

Thermal degradation was assessed by putting the mefenamic acid emulgel in a hot air oven at $80^{\circ} \mathrm{C}$ for $1 \mathrm{w}$. They were performed in triplicate. Samples $(2 \mathrm{~g})$ were transferred into a $50 \mathrm{ml}$ volumetric flask. They were dissolved in ethanol and then sonicated for $15 \mathrm{~min}$. The sample solutions were 2-fold diluted with ethanol and filtered into $2 \mathrm{ml}$ vials.

\section{Oxidative degradation studies}

Oxidative studies were performed in triplicate by pipetting an aliquot of $30 \% \mathrm{H}_{2} \mathrm{O}_{2}$ solution into the sample stock solutions (400 $\mu \mathrm{g} / \mathrm{ml}$ ) to make a final concentration of $1.0 \% \mathrm{H}_{2} \mathrm{O}_{2}$. They were incubated in the dark at room temperature for $1 \mathrm{~h}$. A 2-fold dilution with ethanol was prepared to make the sample solutions $(200$ $\mu \mathrm{g} / \mathrm{ml}$ ) and they were filtered in the vials before injection.

\section{RESULTS AND DISCUSSION}

\section{System suitability test}

It is used to determine the suitability of the chromatographic system to assure the reliable result of drug analysis. It was shown that $\%$ RSD of the peak response was 0.16 and peak asymmetry of mefenamic acid was $1.25 \pm 0.02$. The number of theoretical plates was $12664 \pm 23.11$. It met the general requirement of system suitability.

\section{Specificity study}

HPLC chromatograms showed that mefenamic acid was eluted as a sharp peak at $7.64 \mathrm{~min}$ and there were no peaks of other chemicals in the emulgel preparation that interfered with the drug peak (fig. $2 \mathrm{~A}-2 \mathrm{C}$ ). It was a rapid HPLC method when compared to other 
studies $[20,21]$. The chromatogram of the standard-spiked sample solution also showed a large peak at the same retention time (fig.
2D). These indicated that the proposed method was specific for the determination of mefenamic acid in the emulgel.
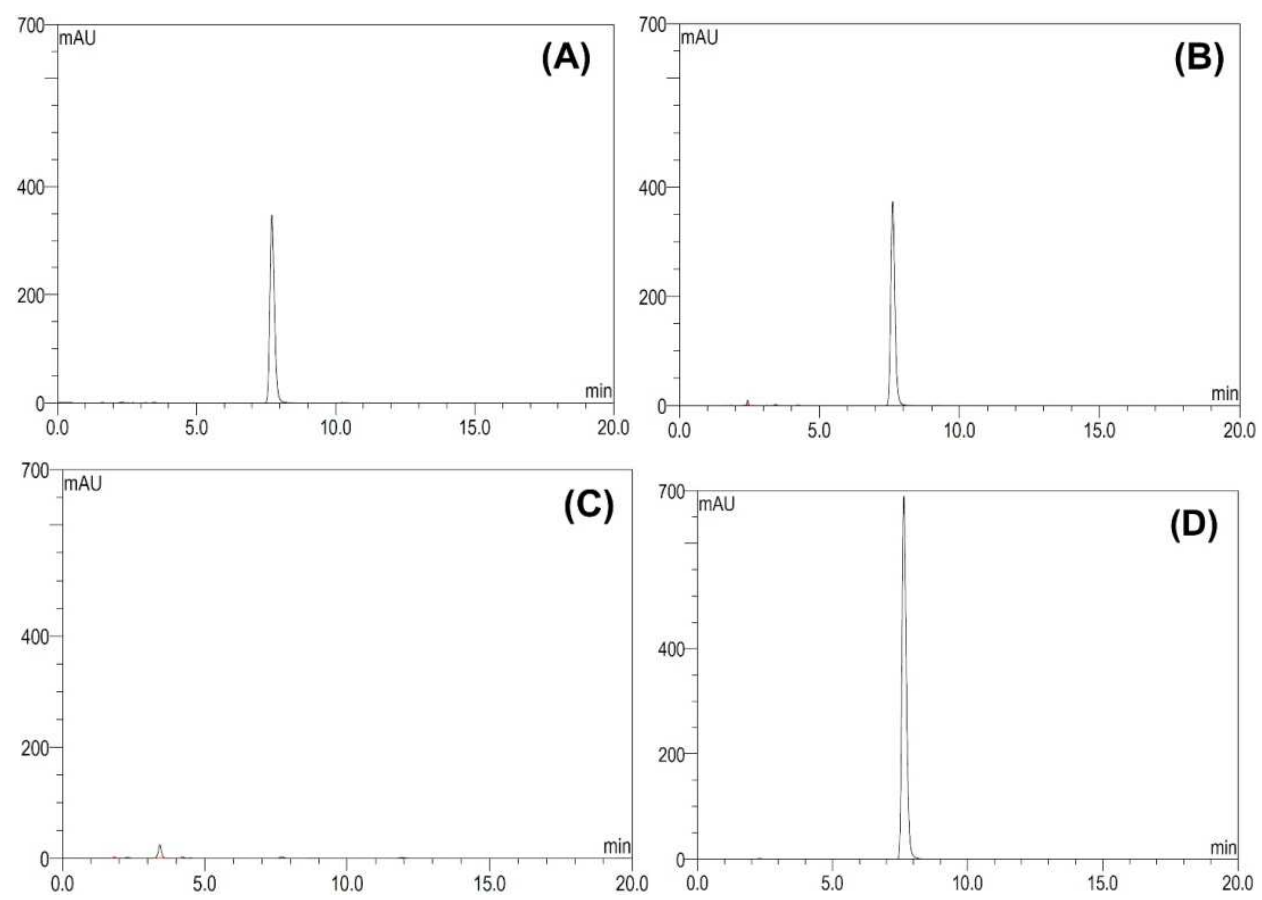

Fig. 2: Chromatograms of (A) standard solution of mefenamic acid (B) sample solution of mefenamic acid emulgel (C) solution of gel base and (D) standard-spiked sample solution

\section{Linearity, LOD, and LOQ studies}

Calibration curves of standard solutions were constructed and the results of regression analysis were summarized in table 1 . It was shown that the curves were linear in the concentration range of $1.29-806 \mu \mathrm{g} / \mathrm{ml}$ with the correlation coefficient $\left(\mathrm{r}^{2}\right)$ of 0.9999 . LOD and LOQ of the method were 4.88 and $14.78 \mu \mathrm{g} / \mathrm{ml}$, respectively. It represented that the proposed method was more sensitive and useful for drug analysis in the emulgel preparation.

\section{Accuracy study}

The accuracy of the proposed method was determined by the synthetic mixture procedure. Different concentrations of mefenamic acid standard in the emulgel $(80 \%, 100 \%$ and $120 \%$ of test concentration) were prepared. Percent drug recovery was found in the range of $99.42 \pm 1.16$ to $102.43 \pm 1.41$ by which the mean percent recovery was $101.10 \pm 1.56$ (table 2). They were in the acceptance criteria in the range of 97-103\% [17]. It indicated that the method was more accurate for drug analysis in the routine work.

Table 1: Regression analysis of calibration curves

\begin{tabular}{ll}
\hline Parameters & Results \\
\hline Linearity range & $1.29-806 \mu \mathrm{g} / \mathrm{ml}$ \\
Slope & 0.3281 \\
y-intercept & 0.2064 \\
SD of y-intercept & 0.4848 \\
Correlation coefficient & 0.9999 \\
LOD & $4.88 \mu \mathrm{g} / \mathrm{ml}$ \\
LOQ & $14.78 \mu \mathrm{g} / \mathrm{ml}$ \\
\hline
\end{tabular}

mean, $\mathrm{n}=3$.

Table 2: Accuracy of the method for analysis of mefenamic acid in drug products

\begin{tabular}{llll}
\hline Level & Concentration added $(\boldsymbol{\mu g} / \mathbf{m l})$ & Concentration measured $(\boldsymbol{\mu g} / \mathbf{m l}) \pm$ SD & \% Recovery \pm SD \\
\hline $80 \%$ & 160 & $163.99 \pm 2.26$ & $102.43 \pm 1.41$ \\
$100 \%$ & 200 & $198.85 \pm 2.33$ & $99.42 \pm 1.16$ \\
$120 \%$ & 240 & $243.34 \pm 2.26$ & $101.39 \pm 0.94$ \\
Overall & & & $101.10 \pm 1.56$ \\
\hline
\end{tabular}

mean $\pm \mathrm{SD}, \mathrm{n}=3$.

\section{Precision study}

The precision of the method was assessed by several injections of the sample solutions. The results of repeatability showed that \%RSD of the response were 1.30 and 0.90 in the first and second day, respectively (table 3). Moreover, the intermediate precision of all sample injections was 1.07 .

They were within the generally acceptable criteria ( $\leq 2.7)$ [17]. Therefore, the proposed method was more precise. 
Table 3: Precision of the method for analysis of mefenamic acid in drug products $(n=6)$

\begin{tabular}{llll}
\hline Sample & Day 1 & Day 2 \\
\cline { 2 - 4 } & Concentration measured $(\boldsymbol{\mu g} / \mathbf{m l})$ & \% LA & Concentration measured $(\boldsymbol{\mu g} / \mathbf{m l})$ \\
\hline 1 & 201.75 & 100.87 & 198.48 \\
2 & 196.83 & 98.36 & 198.53 \\
3 & 202.16 & 101.23 & 196.34 \\
4 & 199.42 & 99.81 & 201.00 \\
5 & 199.57 & 99.98 & 200.60 \\
6 & 196.52 & 98.02 & 200.69 \\
Average & 199.37 & 99.71 & 199.28 \\
Repeatability (\%RSD) & 1.30 & & 0.90 \\
Overall average & 99.67 & & 100.29 \\
Intermediate precision (\%RSD) & 1.07 & & 99.16 \\
\hline
\end{tabular}

mean, $\mathrm{n}=6$.

\section{Forced degradation studies}

The proposed method was used to assess its capability to distinguish mefenamic acid in the emulgel from its degradation products for further use in the stability study. The drugs were degraded in the acid and basic-catalyzed hydrolysis by which the percent drug contents were $90.45 \pm 1.22$ and $93.15 \pm 1.63$, respectively (table 4). The drug was more stable in neutral hydrolysis with the drug content of $100.61 \pm 1.73$ (fig. 3A-3C). Furthermore, the drug content was $94.67 \pm 1.74$ under the oxidation with $1.0 \% \mathrm{H}_{2} \mathrm{O}_{2}$ (fig. 3D). These were consistent with other studies that demonstrated that mefenamic acid was decomposed under the acid and basic hydrolysis and oxidative reaction in which the degraded products were more polar and eluted faster than the parent drug $[20,22]$. Previous studies also showed that the conditions of $\mathrm{pH}$-catalyzed hydrolysis and $\mathrm{H}_{2} \mathrm{O}_{2}$ oxidation were the significant effects on the mefenamic acid degradation and the reaction kinetics was pseudofirst order [23]. However, the drug content was still in the general range of $90-110 \%$. These showed that the emulgel preparation made the mefenamic acid drug stable towards those conditions. However, the drug products were more sensitive to thermal degradation $\left(80^{\circ} \mathrm{C}\right.$ for $1 \mathrm{w}$ ) and the drug content remained $76.21 \pm 1.41$ (fig. 3E). The results were consistent with previous studies that mefenamic acid was susceptible to high temperature and thermal decomposition was nonspontaneous with Gibbs free energy $(\Delta G)$ of $131.01 \mathrm{~kJ} / \mathrm{mol}$ [24]. These results presented that the proposed method was selective and could separate mefenamic acid from the other chemicals and degradation products. It serves as a stability-indicating method that uses for analysis of mefenamic acid in the emulgel preparation during stability studies.
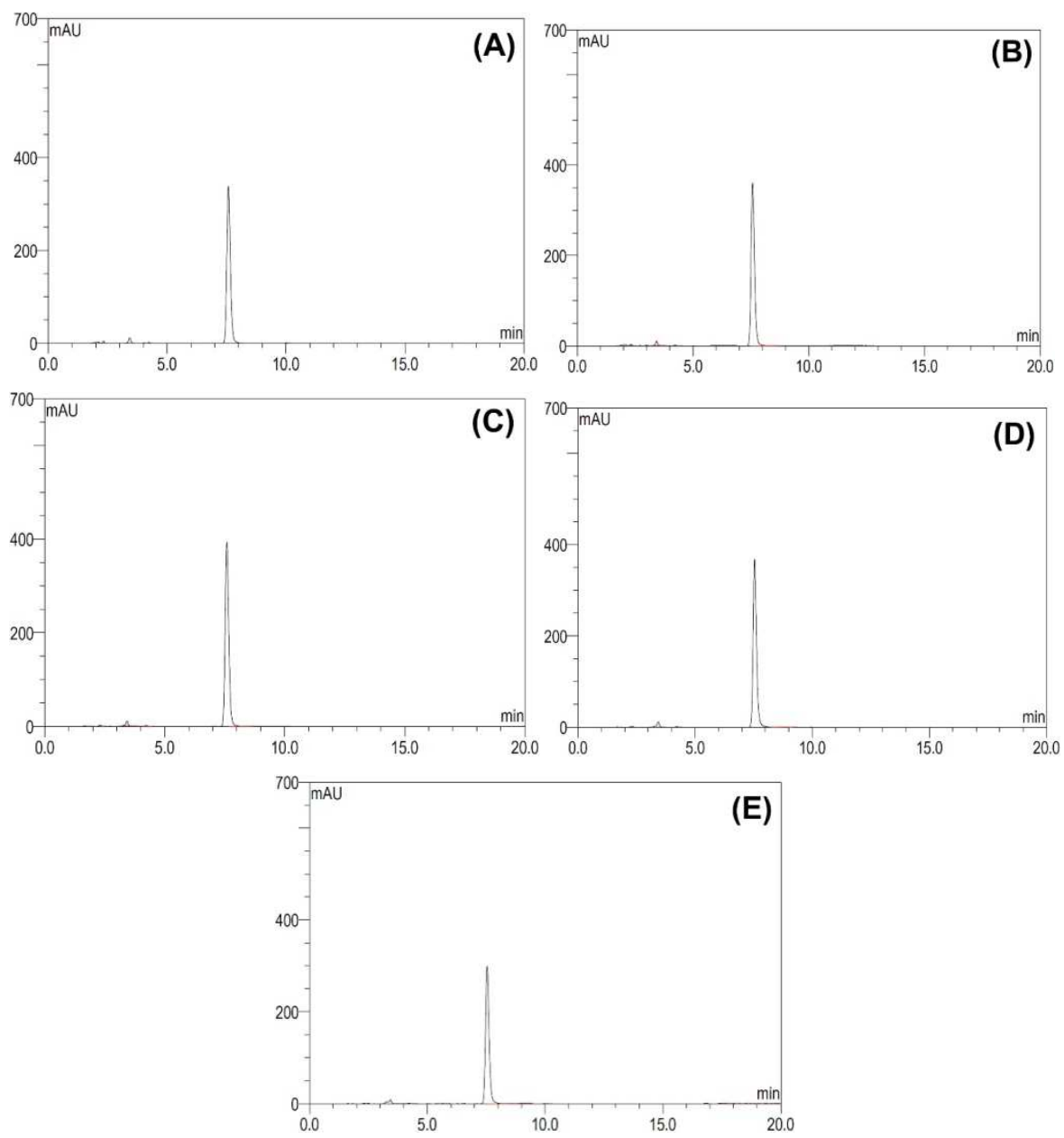

Fig. 3: Forced degradation studies of $1 \%$ mefenamic acid emulgel. (A) acid hydrolysis, (B) basic hydrolysis, (C) neutral hydrolysis, (D) oxidative degradation and (E) thermal degradation 
Table 4: Forced degradation studies of $1 \%$ mefenamic acid emulgel

\begin{tabular}{ll}
\hline Conditions & \% Drug content \\
\hline Acid hydrolysis $0.1 \mathrm{~N} \mathrm{HCl}, 80{ }^{\circ} \mathrm{C} / 1 \mathrm{~h}$ & $90.45 \pm 1.22$ \\
Basic hydrolysis $0.1 \mathrm{~N} \mathrm{NaOH}, 80^{\circ} \mathrm{C} / 1 \mathrm{~h}$ & $93.15 \pm 1.63$ \\
Neutral hydrolysis/Water, $80^{\circ} \mathrm{C} / 1 \mathrm{~h}$ & $100.61 \pm 1.73$ \\
Oxidation $/ 1.0 \% \mathrm{H}_{2} \mathrm{O}_{2} / 1 \mathrm{~h}$ & $94.67 \pm 1.74$ \\
Dry heat $80{ }^{\circ} \mathrm{C} / 1 \mathrm{w}$ & $76.21 \pm 1.41$ \\
\hline
\end{tabular}

mean $\pm S D, n=3$.

\section{Application of the method for determination of mefenamic acid in a topical emulgel}

The proposed method was used to analyze mefenamic acid in an emulgel preparation. It revealed that the mean drug content was $100.77 \pm 1.42 \%$ from 12 different samples. It was in the general acceptant criteria with the labeled amount of 90-110\%. Therefore, the method was more sensitive, precise and accurate to determine mefenamic acid drug in the emulgel.

\section{CONCLUSION}

The developed HPLC method was validated, according to ASEAN guidelines for the validation of analytical procedure for the determination of mefenamic acid in a topical emulgel. It was simple, precise and accurate. Moreover, the chromatographic method could separate the mefenamic acid peak from any degradation products under stress testing. It was served as a stability-indicating method. Therefore, the proposed method can be used for quality control of mefenamic acid in the emulgel and analysis of drug products during the stability study.

\section{ACKNOWLEDGMENT}

This work was supported by a grant from Walailak University .In addition, we would like to thank the Centre of Scientific and Technological Equipments, Walailak University for research facilities.

\section{AUTHORS CONTRIBUTIONS}

All the authors have contributed equally

\section{CONFLICT OF INTERESTS}

Declare none

\section{REFERENCES}

1. Kumar M, Singh D, Bedi N. Mefenamic acid-loaded solid SMEDDS: an innovative aspect for dose reduction and improved pharmacodynamic profile. Ther Delivery 2019; 10:21-36.

2. Nurhikmah W, Sumirtapura YC, Pamudji JS. Dissolution profile of mefenamic acid solid dosage forms in two compendial and biorelevant (FaSSIF) media. Sci Pharm 2016;84:181-90.

3. Modi SV, Patel NJ. Development and evaluation of selfemulsifying drug delivery of a poorly water-soluble NSAID. World J Pharm Pharm Sci 2015;4:462-79.

4. Ajazuddin, Alexander A, Khichariya A, Gupta S, Patel RJ, Giri TK, et al. Recent expansions in an emergent novel drug delivery technology: Emulgel. J Controlled Release 2013;171:122-32.

5. Phad AR, Dilip NT, Ganapathy RS. Emulgel: a comprehensive review for topical delivery of hydrophobic drugs. Asian J Pharm 2018;12(Suppl 2):S382-3.

6. Choudhury H, Gorain B, Pandey M, Chatterjee LA, Sengupta P, Das A, et al. Recent update on nanoemulgel as topical drug delivery system. J Pharm Sci 2017; 106:1736-51.

7. Morcoss MM, Abdelwahab NS, Ali NW, Elsaady MT. Different chromatographic methods for simultaneous determination of mefenamic acid and two of its toxic impurities. J Chromatogr Sci 2017;55:766-72.
8. Al-Qaim FF, Abdullah MP, Othman MR, Khalik WMAWM. Development and validation of HPLC analytical assay method for mefenamic acid tablet (ponstan). Int J Chem Sci 2014;12:6272.

9. Rouini MR, Asadipour A, Ardakani YH, Aghdasi F. Liquid chromatography method for determination of mefenamic acid in human serum. J Chromatogr B Anal Technol Biomed Life Sci 2004;800:189-92.

10. Binhashim NH, Hammami MM. A validated reversed-phase HPLC assay for the determination of mefenamic acid in human plasma. Eur J Pharm Med Res 2016;3:16-21.

11. Kumar A, Chawla P, Porwal P, Rawal RK, Anghore D. Development and validation of mefenamic acid, dicyclomine $\mathrm{HCl}$ and pamabrom in marketed formulation by HPLC. Pharm Anal Acta 2018;9:594.

12. Musthafa F, Suja C, Shuhaib B. Formulation and evaluation studies of emulgel containing mefenamic acid. Eur J Pharm Med Res 2019;6:376-87.

13. Hładon T, Pawlaczyk J, Szafran B. Stability of mefenamic acid in the inclusion complex with cyclodextrin in the solid phase. J Inclusion Phenom Macrocyclic Chem 1999;35:497.

14. Khullar R, Kumar D, Seth N, Saini S. Formulation and evaluation of mefenamic acid emulgel for topical delivery. Saudi Pharm J 2012;20:63-7.

15. Oswal T, Bhosale S, Naik S. Development of the validated analytical method of mefenamic acid in an emulgel (topical formulation). Int J Pharm Sci Res 2014;5:232-7.

16. ASEAN guideline on analytical validation. In: ASEAN guideline. 1st ed. Nonthaburi: Bureau of Drug Control, Food and Drug Administration; 2004. p. 1-18.

17. AOAC International. Appendix F: Guidelines for standard method performance requirements. AOAC Official Methods of Analysis; 2016. p. 1-18.

18. Pandya CP, Rajput SJ. Development and validation of stabilityindicating method RP-HPLC method of acotiamide. Int J Pharm Pharm Sci 2018;10:1-8.

19. Gorja A, Mondal S. Stability indicating method development and validation for the estimation of panobinostat lactatein pharmaceutical dosage forms by UPLC. Int J Pharm Pharm Sci 2018;10:60-5.

20. Dhumal BR, Bhusari KP, Tajne MR, Ghante MH, Jain NS. Stability indicating a method for the determination of mefenamic acid in pharmaceutical formulations by HPLC. J Appl Pharm Sci 2014;4:60-4.

21. Patil PA, Umarkar AR, Bari MM, Barhate SD. Stability indicating RP-HPLC method for determination of drotaverine $\mathrm{HCl}$ and mefenamic acid in pure and pharmaceutical formulation. Am J Adv Drug Delivery 2015;3:110-22.

22. Saleh SF, Dereaya SM, Omar MA. Stability-indicating HPTLC determination of mefenamic acid in bulk drug and pharmaceutical formulations. Int J Chem Anal Sci 2014;5:55-60.

23. Colombo R, Ferreira TC, Ferreira RA, Lanza MR. Removal of mefenamic acid from aqueous solutions by oxidative process: optimization through experimental design and HPLC/UV analysis. J Environ Manage 2016;167:206-13.

24. Ramukutty S, Ramachandran E. Thermal decomposition kinetics of mefenamic acid crystals. Int J Thermodyn Chem Kinet 2016;2:21-4. 